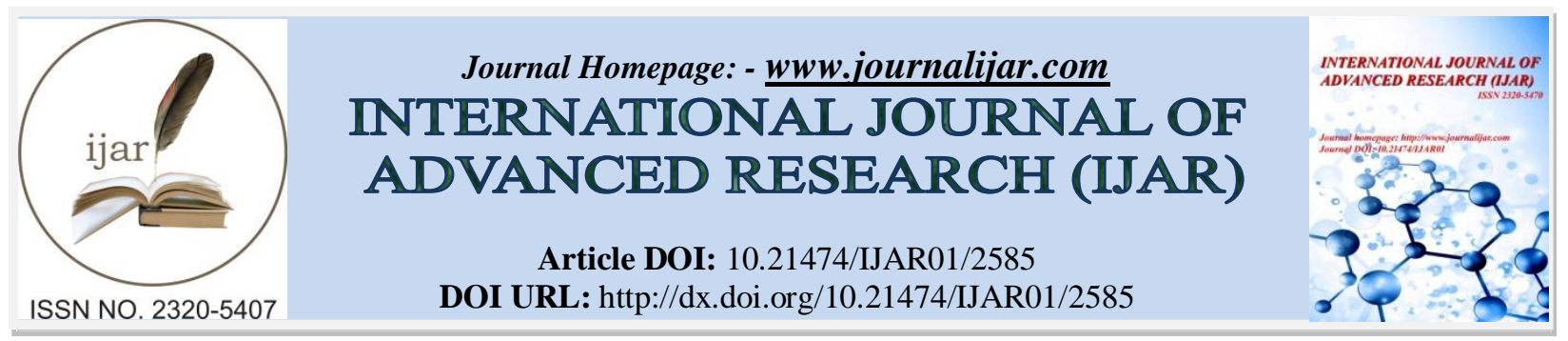

RESEARCH ARTICLE

\title{
ANTIBACTERIAL ACTIVITY OF BIOSYNTHESIZED ZnO NANOPARTICLES AGAINST GRAM POSITIVE (STAPHYLOCOCCUS AUREUS) AND GRAM NEGATIVE (PSEUDOMONAS AERUGINOSA) BACTERIA: A COMPARATIVE STUDY
}

\author{
P. P. Badoni ${ }^{1}$, Goutam Kumar ${ }^{2}$, Reena Purohit ${ }^{2}$, Mahender Singh ${ }^{2}$ and Arun K. Khajuria ${ }^{3}$. \\ 1. Associate Prof., Department of Chemistry, HNB Garhwal University, Campus Pauri, Uttarakhand, India. \\ 2. Research Scholar, Department of Chemistry, HNB Garhwal University, Campus Pauri, Uttarakhand, India. \\ 3. Research Scholar, Department of Botany, HNB Garhwal University, Campus Pauri, Uttarakhand, India.
}

\section{Manuscript Info}

\section{Manuscript History}

Received: 27 October 2016

Final Accepted: 25 November 2016

Published: December 2016

Key words:-

Nanotechnology, Antibacterial behavior, Staphylococcus aureus, Pseudomonas aeruginosa.

\section{Abstract}

Nanotechnology has attracted a lot of attention from every generation: either its new or old generation. Biosynthesized nanoparticles have been used mainly because of their medicinal properties. An important medicinal property of these nanoparticles is their antibacterial behavior against Gram positive and Gram negative bacteria. $\mathrm{ZnO}$ nanoparticles of Arisaema tortuosum (Wallich) Schott, and Rhus parviflora Roxb., leaves extract were synthesized by biochemical (precipitation) method and characterized by X-ray diffraction and UVVisible spectroscopic analysis. At concentration $200 \mu \mathrm{g} / \mathrm{ml}$, their antibacterial activity was evaluated against both Gram positive (Staphylococcus aureus) and Gram negative (Pseudomonas aeruginosa) bacteria and the results showed the antibacterial activity order as:

$\mathrm{ZnO}$ nanoparticles (R. parviflora) $>\mathrm{ZnO}$ nanoparticles (A. tortuosum).

Copy Right, IJAR, 2016,. All rights reserved.

\section{Introduction:-}

Nature has designed various methods for the generation of nano and micro sized inorganic materials which have contributed to the development of relatively new and largely unexplored area of research. And in last few years, it has been observed that researchers have attempted to synthesize nanoparticles within the size range of $100 \mathrm{~nm}$ and these extensive attempts and concerns on nanoparticles is widening due to their vast potential applications in wide areas of science and technology.

It has been reported that inorganic materials interact with biological materials and established a series of nanoparticle/ biological interfaces that depend on colloidal forces as well as dynamic bio-physicochemical interactions. These interactions lead to the formation of new nanomaterial with controlled size, shape, surface chemistry, roughness and surface coatings ${ }^{[2]}$. The synthesis of nanoparticles with specific morphologies and properties is one of the most important aspects of nanoscience which studies materials whose size lies within the nanometer range $\mathrm{e}^{[3]}$. While chemical synthetic procedures can lead to the generation of toxic chemical by-products or require high temperature and/or pressure, biosynthesis of metallic nanoparticles using plant extracts provides a facile and green method of nanoparticle synthesis.

Corresponding Author:- Goutam Kumar

Address:- Research Scholar, Department of Chemistry, HNB Garhwal University, Campus Pauri, 
Several physical and chemical procedures have been reported for the synthesis of $\mathrm{ZnO}$ nanoparticles and currently, biosynthesis method is widely utilized. Plant-mediated biological synthesis of nanoparticles is gaining importance due to its simplicity and eco-friendliness ${ }^{[1]}$. Applications of these nanostructures are seen in catalysis, sensors, water purification, antimicrobial activities. The use of non toxic materials like plant extract for the synthesis of $\mathrm{ZnO}$ nanoparticles offers numerous benefits of medicinal applications.

$\mathrm{ZnO}$ nanoparticles are of antibacterial and antifungal activities even at lower concentrations hence suitable for thin coating applications. The antifungal activity of $\mathrm{ZnO}$ nanoparticles does not affect soil fertility compared to the conventional antifungal agents ${ }^{[11]}$. The bacterium and fungal lipid bi-layers get ruptured due to cytotoxic behavior of $\mathrm{ZnO}$ nanoparticles resulting in the drainage of the cytoplasmic contents ${ }^{[12]}$. Even antibacterial agents were developed against a wide range of microorganisms to control the bacterial infection ${ }^{[8]}$.

At last, in the present work, $\mathrm{ZnO}$ nanoparticles of Arisaema tortuosum (Wallich) Schott, and Rhus parviflora Roxb., leaves extract were synthesized by biochemical (precipitation) method and characterized by X-ray diffraction and UV-Visible spectroscopic analysis. These nanoparticles showed wonderful antibacterial activity against both Gram positive (Staphylococcus aureus) and Gram negative (Pseudomonas aeruginosa) bacteria.

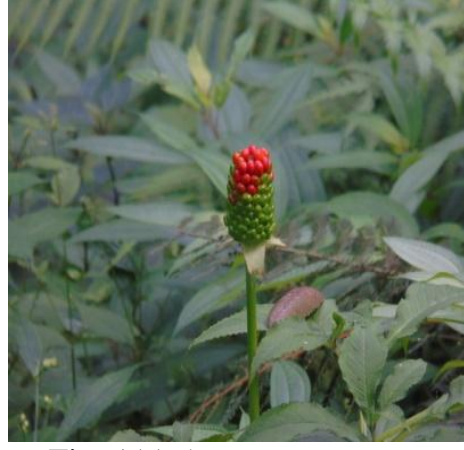

Fig. 1(a) Arisaema tortuosum

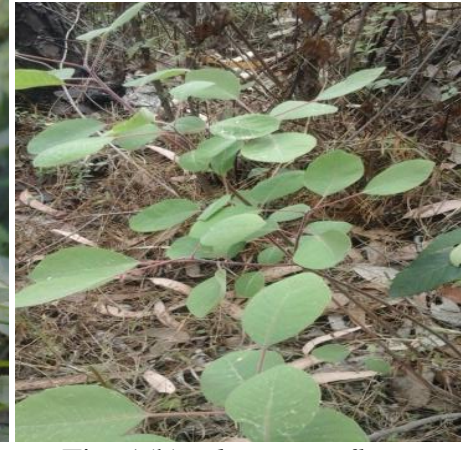

Fig. 1(b) Rhus parviflora

Fig. 1:- showing images of the plants (a) Arisaema tortuosum and (b) Rhus parviflora used in this work.

\section{Materials and Methods:- \\ Materials: Collection:-}

The leaves of both plants were collected from Hilly area of District Pauri (Uttarakhand), India. Zinc acetate dihydrate and sodium hydroxide pellets were purchased from Merck-Millipore (India).

\section{Methods: Preparation of Leaves Extract and Zinc Oxide Nanoparticles:-}

The leaves extract was prepared by mixing $05 \mathrm{gm}$ of dried leaves powder with $100 \mathrm{~mL}$ deionized water in $250 \mathrm{~mL}$ of Erlenmeyer flask and boiled for $20-30$ minutes at $70^{\circ} \mathrm{C}$. Then the leaves extract was collected in separate conical flask by filtering it through Whatman filter paper no.1 and stored for further studies.

But for the synthesis of $\mathrm{ZnO}$ nanoparticles, $50 \mathrm{ml}$ of leaves extract was taken and heated to $60-70^{\circ} \mathrm{C}$ using a magnetic stirrer heater. $0.1 \mathrm{M}$ Zinc acetate dihydrate and $1 \mathrm{M} \mathrm{NaOH}$ solution were added to it with constant stirring. This mixture is then boiled until it reduced to a deep color precipitate. The color precipitate was centrifuged and washed with deionized distilled water. The washing and centrifuging was repeated several times using water and ethanol. The obtained material was dried at $30^{\circ} \mathrm{C}$ for 12 hours in oven. Finally, to get a finer and uniform nature for characterization, the color dried material was mashed in a mortar-pestle .

\section{Characterization:-}

The synthesized $\mathrm{ZnO}$ nanoparticles were characterized by XRD and UV-Vis spectroscopic analysis from USIC, HNBGU and SAIF \& CIL, PU, India, respectively. 


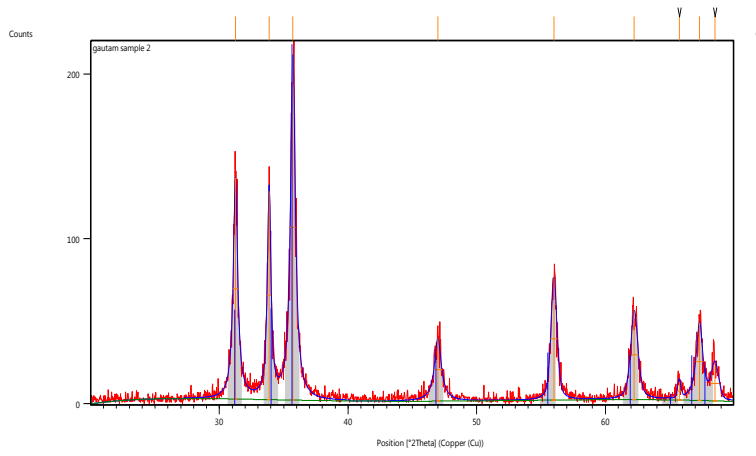

Fig. 2(a)

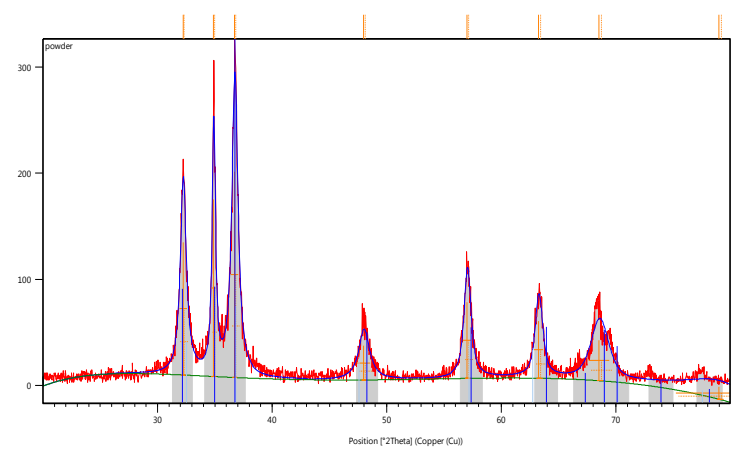

Fig. 2(b)

Fig. 2;- XRD patterns of $\mathrm{ZnO}$ nanoparticles of a) A. tortuosum and b) $R$. parviflora leaves extracts showed crystalline nature of these nanoparticles and the average size of nanocrystal was estimated according to Scherer's equation:

$$
\mathbf{d}=K \lambda / \boldsymbol{\beta} \operatorname{Cos} \theta
$$

Where, ' $d$ ' is the crystallite size, ' $\lambda$ ' the $\mathrm{X}$-ray wavelength $(\mathrm{CuK} \alpha)$, ' $\mathrm{K}$ ' is the shape factor, ' $\beta$ ' the Full Width Half Maximum (FWHM) and ' $\theta$ ' is the diffraction angle. It is calculated that the average crystallite size of $\mathrm{ZnO}$ nanoparticles of $A$. tortuosum and $R$. parviflora leaves extracts are $<20$ and $<25 \mathrm{~nm}$, respectively.
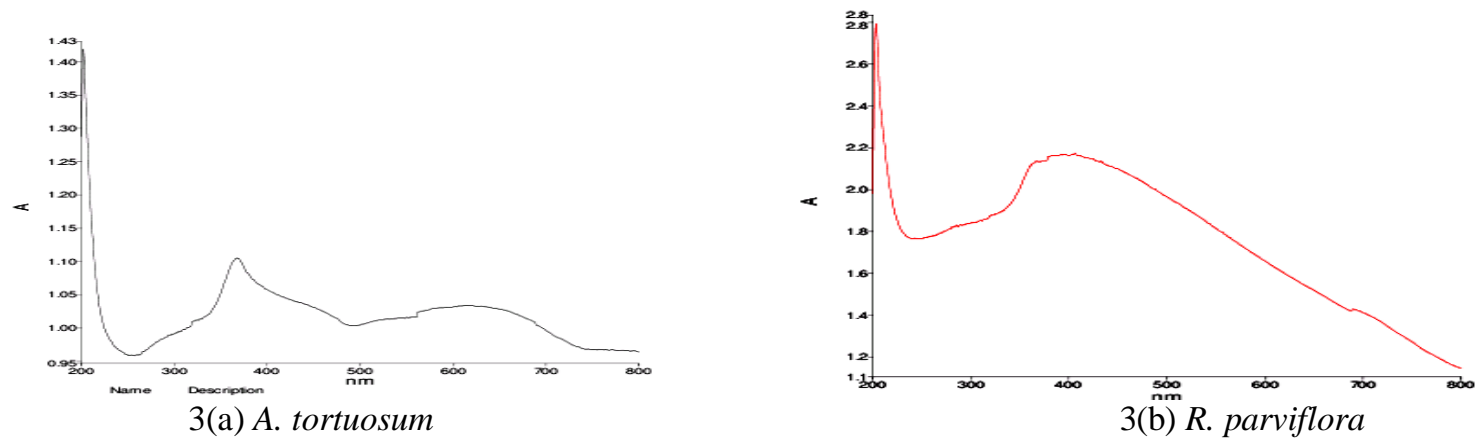

Fig. 3:- UV-Visible spectra of $\mathrm{ZnO}$ nanoparticles of a) A. tortuosum and b) $R$. parviflora leaves extracts showed absorbance in the range of $355-375 \mathrm{~nm}$ for both nanoparticles. It can be predicted from the spectra that the formation of $\mathrm{ZnO}$ nanoparticles of both plants has been taken place.

\section{Antibacterial Activity:-}

In the following Fig. 4 (a \& b), 'A' and 'R' terms are used for A. tortuosum and $R$. parviflora leaves extract mediated synthesized $\mathrm{ZnO}$ nanoparticles for the evaluation of their antibacterial activity.

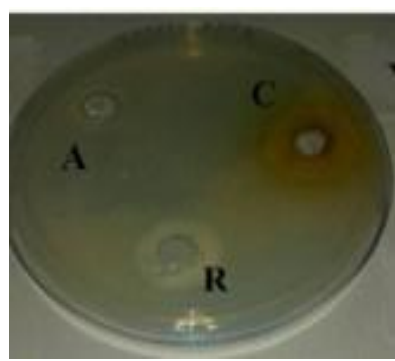

4(a) Staphylococcus aureus

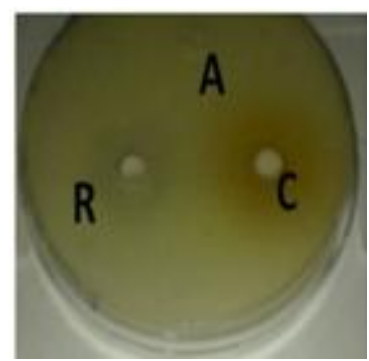

4 (b) Pseudomonas aeruginosa

Fig. 4:- The minimum diameter of zone of inhibition of $\mathrm{ZnO}$ nanoparticles of $A$. tortuosum leaves extract can be seen against Staphylococcus aureus and Pseudomonas aeruginosa where as maximum for $R$. parviflora against Staphylococcus aureus and Pseudomonas aeruginosa pathogens at concentration $200 \mu \mathrm{g} / \mathrm{ml}$. 
Table 1:- Antibacterial Activity Nanoparticles.

\begin{tabular}{|l|l|l|}
\hline Nanoparticle & \multicolumn{2}{|c|}{ Diameter of zone of inhibition (mm) } \\
\hline & $\begin{array}{l}\text { Staphylococcus aureus } \\
\text { (Gram positive) }\end{array}$ & $\begin{array}{l}\text { Pseudomonas aeruginosa } \\
\text { (Gram negative) }\end{array}$ \\
\hline $\mathrm{A}(200 \mu \mathrm{g} / \mathrm{ml})$ & 18.0 & 15.0 \\
\hline $\mathrm{R}(200 \mu \mathrm{g} / \mathrm{ml})$ & 25.0 & 27.0 \\
\hline
\end{tabular}

Table 1. Values of diameter of zone of inhibition in $\mathrm{mm}$ of both nanoparticles showing the efficiency of ' $\mathrm{R}$ ' nanoparticle over the other i.e. 'A' against the Staphylococcus aureus-Gram positive and Pseudomonas aeruginosaGram negative bacteria.

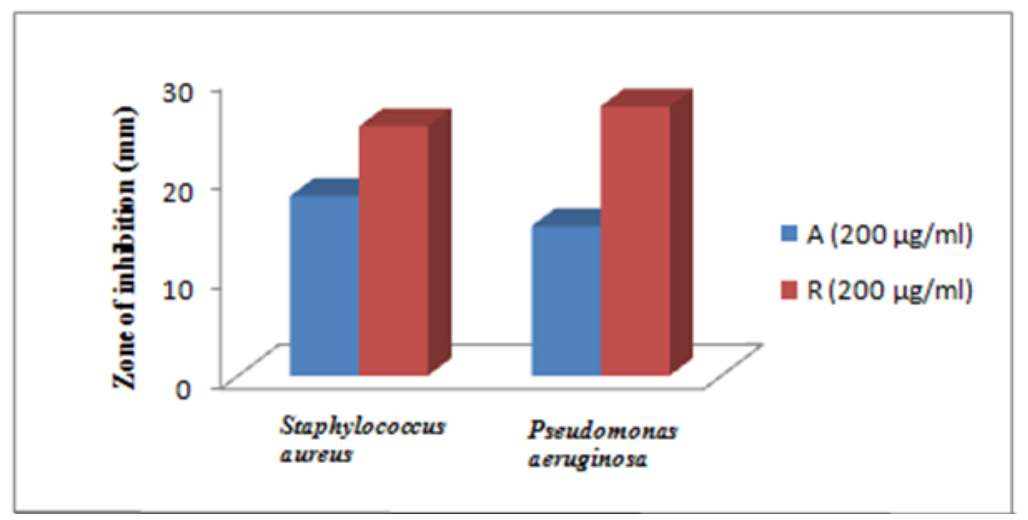

Fig. 5:- Histogram of antibacterial activity of $\mathrm{ZnO}$ nanoparticles of A. tortuosum (A) and R. parviflora $(\mathrm{R})$ is describing the potential of both nanoparticles. Clearly, it can be seen that the antibacterial potential of ' $R$ ' nanoparticles is much higher than the potential of 'A'.

\section{Conclusion:-}

From the above results, it is concluded that these nanoparticles are crystalline in nature and of average size in nanometer range. At concentration $200 \mu \mathrm{g} / \mathrm{ml}$, antibacterial activity of these biosynthesized $\mathrm{ZnO}$ nanoparticles against both Gram positive (Staphylococcus aureus) and Gram negative (Pseudomonas aeruginosa) bacteria showed the following order:

\section{ZnO nanoparticles (R. parviflora) $>$ ZnO nanoparticles (A. tortuosum)}

\section{Acknowledgment:-}

Gratefully acknowledge the financial support from the University Grants Commission (UGC), New Delhi in the form of Junior Research Fellowship.

\section{References:-}

1. Fatimah, I., Pradita, R. Y. and Nurfalinda, A. (2016): Plant Extract Mediated of ZnO Nanoparticles by using Ethanol Extract of Mimosa pudica Leaves and Coffee Powder. Procedia Engineering, 148: 43-48.

2. Poovizhi, J. and Krishnaveni, B. (2015): Synthesis, Characterization and Antimicrobial Activity of Zinc Oxide Nanoparticles Synthesized from Calotropis procera. International Journal of Pharmaceutical Sciences and Drug Research, 7(5): 425-431.

3. Varghese, E. and George, M. (2015): Green Synthesis of Zinc Oxide Nanoparticles. International Journal of Advance Research in Science and Engineering, 4(1): 307-314.

4. Tamanna Bhuyan, Kavita Mishra, Manika Khanuja, Ram Prasad and Ajit Varma, (2015): Biosynthesis of Zinc Oxide Nanoparticles from Azadirachta indica for Antibacterial and Photocatalytic applications. Materials Science in Semiconductor Processing, 32: 55-61.

5. Ramesh, M., Anbuvannan, M. and Viruthagiri, G. (2015): Green Synthesis of ZnO Nanoparticles using Solanum nigrum leaf extract and their Antibacterial Activity. Spectrochimica Acta Part A: Molecular and Biomolecular Spectroscopy, 136: 864-870.

6. Bisht, N. S. and Khajuria, A. K. (2014): Ethno-medicinal Plants of Tehsil Kathua, Jammu \& Kashmir. Journal of Mountain Research, 9: 1-12. 
7. Salam, H. A., Sivaraj, R. and Venckatesh, R. (2014): Green synthesis and characterization of Zinc Oxide Nanoparticles from Ocimum basilicum L. var. purpurascens Benth.-Lamiaceae leaf extract. Materials Letters, 131: $16-18$.

8. Jayaseelan, C., Rahuman, A. A., Kirthi, A.V., Marimuthu, S., Santhoshkumar, T., et al. (2012): Novel Microbial Route to Synthesize ZnO Nanoparticles using Aeromonas hydrophila and their Activity against Pathogenic Bacteria and Fungi. Spectrochimica acta, Part A, Molecular and Biomolecular Spectroscopy, 90: 7884.

9. Shrestha, S., Park, J. H., Lee D. Y., Cho, J. G., Cho, S., Yang, H. J., et al. (2012): Rhus parviflora and its biflavonoid constituent, rhusflavone, induce sleep through the positive allosteric modulation of GABAAbenzodiazepine receptors. Journal of Ethnopharmacology, 142: 213-20.

10. Raghupathi, K.R., Koodali, R.T. and Manna, A.C. (2011): Size-dependent Bacterial Growth Inhibition and Mechanism of Antibacterial Activity of Zinc Oxide Nanoparticles. Langmuir: The ACS Journal of Surfaces and Colloids, 27(7): 4020-28.

11. Sharma, D., Rajput, J., Kaith, B., Kaur, M. and Sharma, S. S. (2010): Synthesis of ZnO Nanoparticles and Study of their Antibacterial and Antifungal Properties. Thin Soil Films, 519: 1224-29,.

12. Feris, K., Otto, C., Tinker, J., Wingett, D., et al. (2010): Electrostatic Interactions Affect Nanoparticle-mediated Toxicity to Gram negative bacterium Pseudomonas aeruginosa. PAO1. Langmuir: The ACS Journal of Surfaces and Colloids, 26(6): 4429-36.

13. Dhuna, V., Bains, J. S., Kamboj, S. S., et al.( 2005): Purification and Characterization of a lectin from Arisaema tortuosum having in-vitro Anticancer Activity against Human Cancer cell lines. Journal of Biochemistry and Molecular Biology, 38: 526-32. 